\title{
Design de Exposição Elementar: Uma ferramenta visual para auxiliar projetos colaborativos.
}

\author{
Elementary Exhibition Design: A visual tool to assist collaborative projects.
}

\author{
Marina Moraes, Adriano Heemann
}

design de exposição, projetos colaborativos, colaboração

\begin{abstract}
Em exposições um dos desafios do/a gerente de projetos compreende partir do genérico para o particular, interpretando estímulos e interações de equipes multidisciplinares. Outro fator importante é a definição dos elementos essenciais para a execução no prazo com os recursos disponíveis. Para investigar como a colaboração está inserida em projetos de exposições foi aplicado o método "grounded theory", teoria fundamentada em dados. A estrutura do corpus de análise é formada por entrevistas semiestruturadas com diretoras das empresas de Design de Exposições e estudo de projetos. Como resultado foi desenvolvida a ferramenta "Design de Exposições Elementar", este modelo se apresenta orgânico, podendo ser ampliado por pesquisadores/as e projetistas interessados na discussão desta modalidade de projeto no campo do Design. O presente estudo busca contribuir para a aplicação da colaboração e compreensão dos seus desafios, a investigação resulta de uma pesquisa que observou práticas projetivas em um contexto ainda pouco explorado pela literatura do Design brasileiro. Em conclusão, a visualização das etapas do processo criativo permite organizar conceitos elementares e observar pontos de convergência para compreensão dos desafios iniciais de um projeto complexo.
\end{abstract}

exhibition design, collaborative projects, collaboration

In exhibition design, one of the challenges faced by the project manager is to start from the generic to the particular, interpreting motivation and interactions of multidisciplinary teams. Another important factor is the definition of the essential elements for the execution on time with the available resources. In order to investigate how collaboration is inserted in exhibition, the "grounded theory", method based on data was applied. The structure of the analysis corpus is formed by semi-structured interviews with directors of Exhibition Design companies and the study of projects. As a result, a visual tool called "Elementary Exhibition Design" was developed to visualize the information. This model is organic and can be expanded by researchers and designers interested in discussing this type of project in the field of Design. The present study seeks to contribute to the application of collaboration and understanding of your challenges, this investigation results from a research that observed projective practices in a context still little explored by the Brazilian Design literature. In conclusion, visualizing the stages of the creative process allows organizing elementary concepts and observing points of convergence to understand the initial challenges of a complex project.

Anais do $10^{\circ} \mathrm{CIDI}$ e $10^{\circ} \mathrm{CONGIC}$

Kelli C.A.S. Smythe, Rafael de Castro Andrade (orgs.)

Sociedade Brasileira de Design da Informação - SBDI

Curitiba | Brasil | 2021
Proceedings of the $10^{\text {th }} \mathrm{CIDI}$ and $10^{\text {th }}$ CONGIC

Kelli C.A.S. Smythe, Rafael de Castro Andrade (orgs.)

Sociedade Brasileira de Design da Informação - SBDI Curitiba | Brazil | 2021 


\section{Introdução}

No Design de Exposições são necessários inúmeros esforços para promover o "alinhamento temporal" nos projetos, estes geralmente possuem prazos inegociáveis para a execução, devido à sua inauguração ou lançamento. Além disso, os gestores/as necessitam coordenar equipes multidisciplinares para concepção de identidade visual, percursos, cenários, iluminação, conteúdos audiovisuais, entre outros elementos compositivos.

Neste artigo, será apresentado parte do resultado de uma pesquisa de mestrado que investigou o fenômeno da colaboração no gerenciamento de projetos expositivos. Através do levantamento bibliográfico sistemático constatou-se uma lacuna teórica, o número reduzido de pesquisas que descrevessem com clareza esta modalidade de projetos. O problema de pesquisa se estruturou com base neste contexto: como a colaboração está inserida na produção de projetos no Design de Exposições?

O presente estudo entende o termo colaboração como: uma ação produtiva ou criativa que surge a partir de um grupo comprometido, buscando um resultado em comum. A relação entre os membros depende da confiança e da dedicação de cada parte envolvida. Esta definição pode ser aplicada a "cooperação", "compartilhamento" e "trabalho em equipe", o que difere a colaboração dos termos anteriores são os níveis de comprometimento e reciprocidade na realização das tarefas (Heemann et al. 2008).

O método da pesquisa se dividiu em duas etapas, na primeira foi realizado o levantamento bibliográfico dos temas "colaboração" e "design de exposições", através das revisões sistemática e assistemática buscando investigar ênfases e lacunas do conhecimento. Este artigo não se aprofunda nesta parte, buscando destacar a construção do recurso visual "Design de Exposições Elementar" e a sua aplicação.

Após o levantamento da teoria de base, partiu-se para a segunda etapa da pesquisa, a aplicação do método Grounded Theory (Teoria Fundamentada em Dados), estruturado por Glaser e Strauss (1967). O corpus da pesquisa teve como base o levantamento de informações com empresas brasileiras do Design de Exposições, atuantes no setor há mais de dez anos no Brasil, esses dados foram levantados em entrevistas semiestruturadas e estudo de projetos. A construção e descrição dos detalhes é apresentada na seção de método da pesquisa.

Com a análise destas informações constatou-se a aplicação da colaboração nas empresas, mas a ausência da sistematização e registro dos processos colaborativos. Desta forma, surgiu o interesse de representar as informações levantadas de forma clara e objetiva, através de uma ferramenta informativa denominada "Design de Exposições Elementar", o presente artigo tem como objetivo apresentar o processo de construção e sistematização visual. É importante ressaltar que esse instrumento não se configura como um modelo prescritivo, mas como um caminho inicial para compreensão dos elementos essenciais para colaboração em projetos desta natureza. 


\section{Método}

O método aplicado na pesquisa foi o Grounded Theory (Teoria Fundamentada em Dados) estruturado por Glaser e Strauss (1967) e de natureza qualitativa. No levantamento e processamento de dados foram consultados os autores Bauer e Gaskell (2002), Glaser e Strauss (1967), Strauss e Corbin (1998), Holstein e Gubrium (2008). Na delimitação do escopo da pesquisa, foram selecionadas empresas brasileiras que alcançaram viabilidade financeira no médio prazo, com mais de dez anos de fundação. Para ter acesso a estes dados foi realizada uma pesquisa junto à Receita Federal, no Cadastro Nacional de Pessoa Jurídica (CNPJ).

Como efeito deste levantamento, foram selecionadas quinze empresas, nas quais posteriormente foram analisadas e classificadas conforme sua área de atuação: generalista, cenografia, tecnologia, design gráfico, iluminação, sonorização e audiovisual. A caracterização foi realizada no que tange as atividades principais, a partir das informações concedidas pelas próprias empresas em seus sites e em diversos meios de apresentação institucional. Além desses dados, foram coletados os contatos de gestores/as, ação que possibilitou o acesso online às entrevistadas. Nesta etapa o número da amostra foi reduzido para cinco, na qual três delas estabeleceram o retorno do contato com disponibilidade em tempo hábil para as entrevistas semiestruturadas, realizadas em caráter presencial no final do ano de 2019.

Aqui destacamos dois fatos importantes sobre o período, em primeiro lugar a visita às empresas que aconteceram em um momento conturbado de transição política presidencial no Brasil. Devido a questões econômicas e culturais, as empresas passavam por reestruturação nos seus processos, atividades e atuações nas áreas de projetos. A transição deste cenário apareceu na narrativa das entrevistadas e posteriormente, na análise dos dados. Em segundo lugar, a pesquisa foi realizada um ano anterior a pandemia "de COVID-19", a entrevista semiestruturada presencial era o procedimento indicado por Bauer e Gaskell (2002) para interação aprofundada com entrevistado/a.

No contexto atual, esse procedimento vem sendo transformado pelo fenômeno da digitalização, fator resultante do distanciamento social no ano de 2020 - 2021. Cabe aqui ressaltar que os processos políticos, culturais sociais e tecnológicos continuam transformando a área do Design de Exposições, assim como sua forma de projetar e coordenar suas complexidades.

Retomando o raciocínio do escopo da pesquisa, em um primeiro momento o recorte se estabeleceu na cidade de São Paulo, devido a forte concentração destas empresas. No decorrer do estudo, houve a ampliação para incluir a empresa "SuperUber", sediada no Rio de Janeiro. Por fim, o estudo abordou três empresas: "Burkhardt Leitner Brazil", "Mandacaru Design" e "SuperUber" e quatro entrevistadas Bebel Abreu, Liana Brazil, Manaíra Abreu e Mônica Kalman.

Com a delimitação das empresas participantes, a próxima ação foi o desenvolvimento de um protocolo de coleta de dados, para aplicação da teoria estruturada e a descrição dos cuidados éticos da pesquisa. Os dados coletados nas entrevistas foram de encontro com as informações disponíveis nos sites das empresas e os vídeos de produção dos projetos, no caso da empresa SuperUber que disponibiliza esse formato para divulgação do seu trabalho. 
O uso de entrevistas semiestruturadas possibilitou flexibilidade para alteração na ordem das perguntas, proporcionaram também fluidez para aprofundar em temas específicos propostos pelas entrevistadas.

No dia das entrevistas, agendadas anteriormente por e-mail, houve a apresentação do protocolo de coleta de dados para a leitura e confirmação pelas entrevistadas. Também foi entregue para assinatura o termo de consentimento livre esclarecido apresentando detalhes dos procedimentos executados no decorrer da pesquisa e seus fins acadêmicos da entrevista e do material coletado. $\mathrm{O}$ aparato de equipamentos utilizado para a captação foi um gravador zoom h1, uma câmera DSLR (Canon) um tripé e fichas das imagens dos projetos analisados.

$\mathrm{Na}$ etapa de tratamento e processamento dos dados ocorreu o retornou do contato. As entrevistas foram transcritas e enviadas para as entrevistadas para conferência do conteúdo, após a devolutiva, elas foram revisadas com as alterações solicitadas. Após esse minucioso cuidado com o conteúdo coletado houve uma leitura criteriosa e seleção do corpus desse trabalho.

Em síntese, a seguir são apresentados os passos realizados para a construção e a investigação do método de pesquisa (Moraes, 2020):

1. Levantamento teórico

2. Coleta de dados

3. Tratamento e processamento dos dados

4. Discussão

5. Conclusão

No diagrama (figura 1) pode ser observado o detalhamento de cada uma destas etapas do método, apresentam-se os modos de planejamento, a condução da coleta e o processamento de dados. Os resultados de cada passo são demonstrados na parte externa na cor cinza. 
Figura 1 - Diagrama geral do método de pesquisa. Fonte: Autores

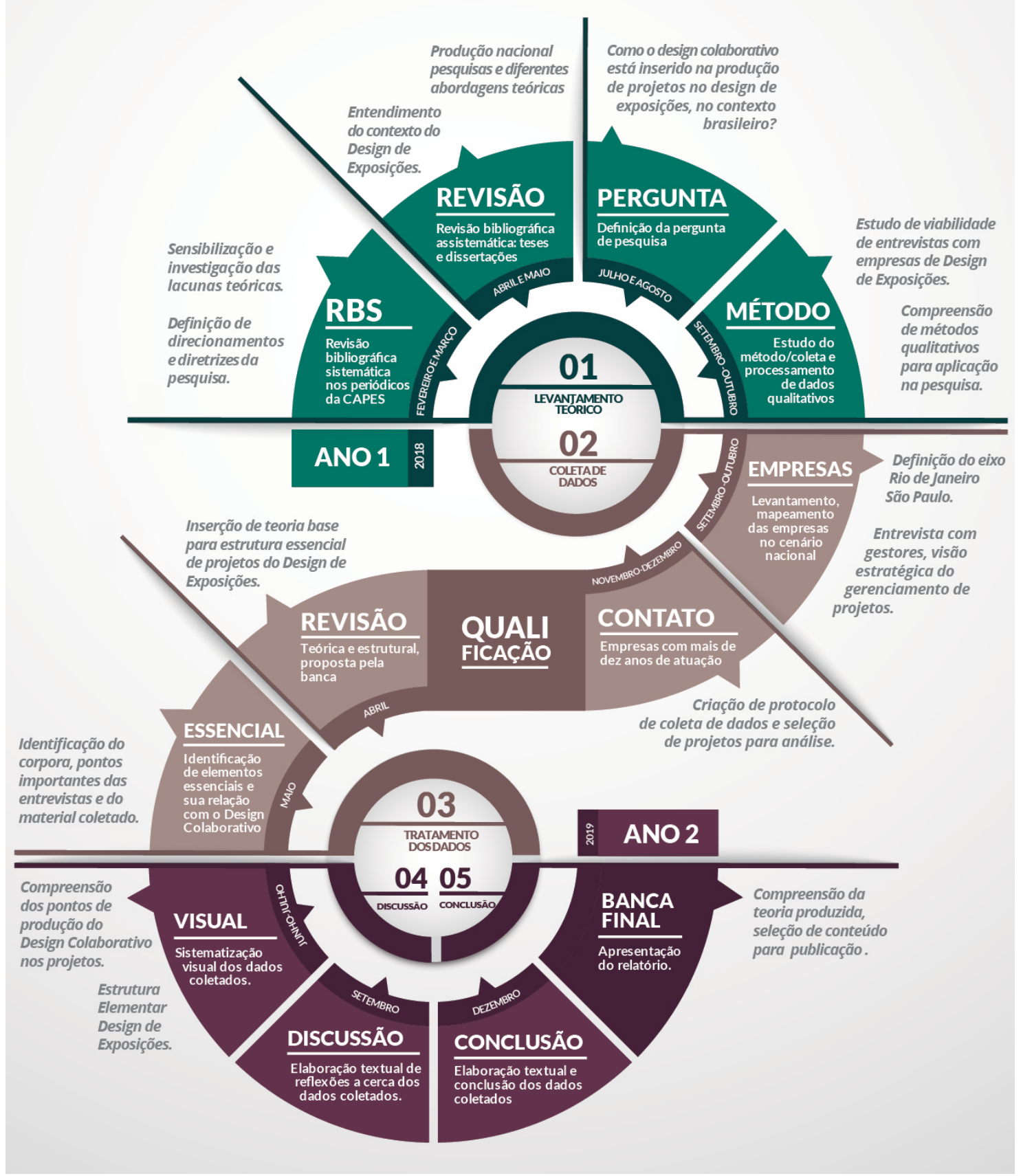

No diagrama, além da visualização das etapas consta a evolução temporal de cada fase. Como pode ser observado na representação gráfica das casas com triângulos direcionais, trata-se de 24 meses e as curvas ilustram os 2 anos de pesquisa. Esta ferramenta gráfica e informativa esteve presente fisicamente durante todo o processo, como um banner impresso, disposto no escritório para interferência de papeis coloridos. Dessa forma, essa ferramenta foi norteadora e auxiliou na compreensão dos passos a serem seguidos além dos resultados alcançados em cada etapa. 
A seguir serão apresentadas, as empresas que participam do estudo:

- A "SuperUber" é uma empresa que desenvolve experiências misturando arte, tecnologia, arquitetura e design, com mais de 250 projetos finalizados. "Usamos a tecnologia para reconectar pessoas, através de projetos presenciais buscamos ideias mais colaborativas do que individuais nas exposições" (Brazil, 2019).

- A "Mandacaru Design" é um estúdio de produção e comunicação, sediado em São Paulo desde 2005, criado por Manaíra Abreu, designer gráfica e Bebel Abreu, arquiteta. O estúdio conta com uma extensa rede de colaboradores prestando serviços de fotografia, ilustração, design de produto, tradução, assessoria de imprensa, entre outros. A empresa se define como: "Uma produtora cultural que cria experiências únicas a partir de conhecimentos relevantes" (Mandacaru, 2020).

- A "Burkhardt Leitner Brazil" é uma empresa instalada no Brasil que exporta a tecnologia de estruturas modulares expositivas da Alemanha. Para atender os mercados culturais e promocionais brasileiros, no decorrer dos anos foi necessária a adaptação dos produtos pela empresa, em parceria com curadores e produtores (Kalman, 2020).

A partir desta seleção houve o levantamento dos projetos que foram de encontro com o escopo da pesquisa, a busca aconteceu em sites das empresas e apresentações institucionais. Levou-se em consideração também o modo como os projetos foram divulgados, através das indicações de colaboração com empresas externas. Foram selecionados trabalhos de compreensão universal, de maneira a não delimitar aspectos regionais na sua produção. Outro ponto considerado foi a multidisciplinaridade da equipe participante, para possibilitar discussões das quais esse estudo se propõe.

É importante ressaltar que a pesquisa analisa projetos que possuem natureza física, ou seja, sua estrutura é projetada para convidar o espectador à interação e imersão em seus elementos estruturais. Foi também considerado o potencial narrativo empregado, a riqueza pictórica dos elementos, a ambientação cenográfica, o caráter lúdico da experiência e seu aspecto inovador na proposta do Design de Exposição. No processo de investigação foram percebidas outras facetas de interesse: a coerência entre proposta e a realização, a inerência e sua fixação em um local determinado para entender o funcionamento logístico de produção. Em resumo, são apresentados a seguir os itens analisados para seleção.

\section{Critérios de seleção dos projetos:}

- Abordagem narrativa de compreensão universal

- Processos multidisciplinares

- Análise dos processos de produção, disponíveis no site das empresas

- Seleção de um projeto permanente e de um segundo efêmero, como forma de compreensão da complexidade nesses diferentes cenários. 
Foram selecionados dois projetos por empresas, atendendo ao escopo e aos critérios acima citados. Além de apresentarem características de complexidade estrutural, os projetos foram mencionados nas entrevistas, e narrados pelas entrevistadas como relevantes para construção colaborativa. A figura 2 apresenta a sistematização dos dados, através da extração, limpeza e agrupamento de informações, com base no problema de pesquisa.

Figura 2 - Procedimento de transformação dos dados. Fonte: Autores

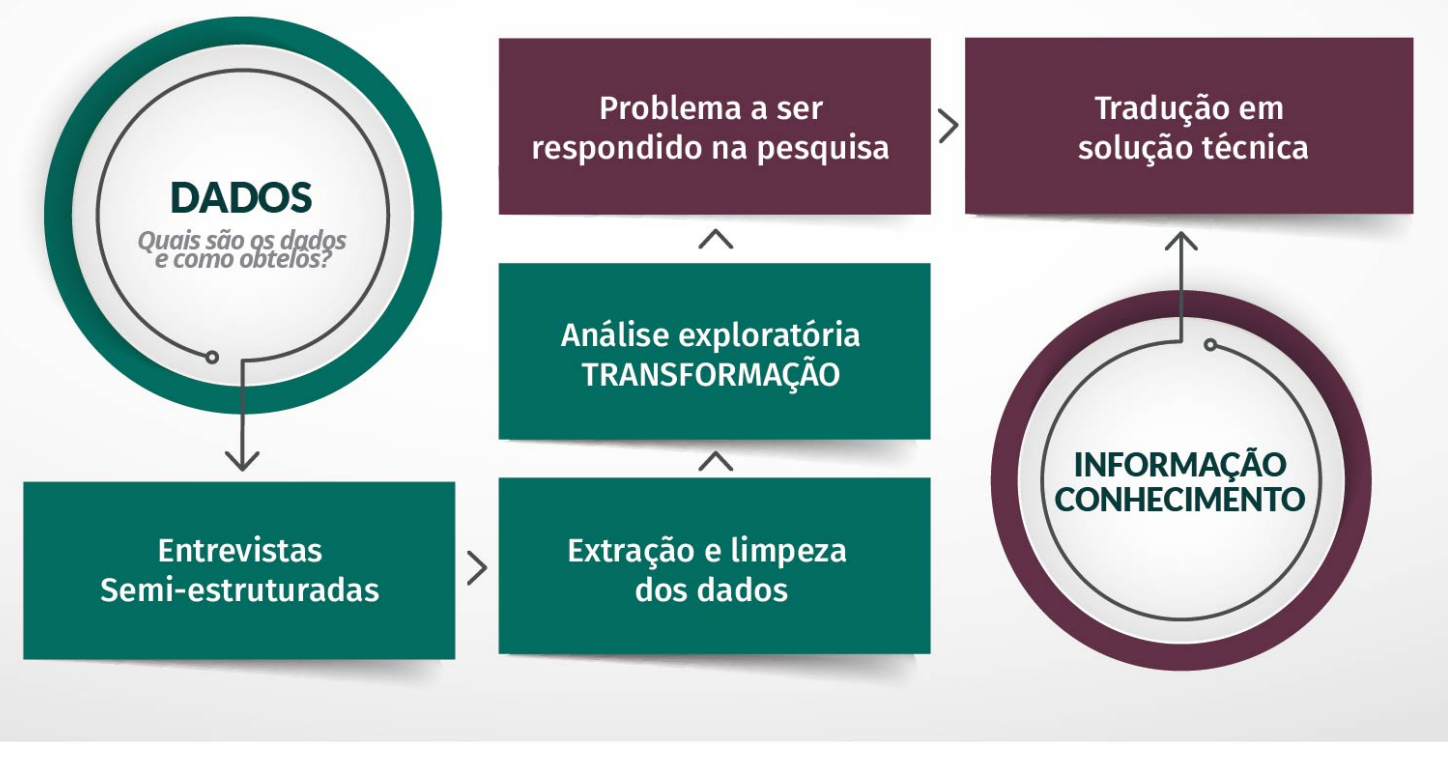

$\mathrm{Na}$ etapa de transformação dos dados buscou-se investigar as seguintes perguntas:

- Há OCORRÊNCIA da colaboração no desenvolvimento de projetos?

- Há SISTEMATIZAÇÃO e registro estrutural desses processos?

- Há DIVULGAÇÃO da utilização desses processos?

A análise de dados foi feita após a transcrição das entrevistas e a análise dos projetos, tendo como base a teoria de Scaletsky (2016), que consiste em reunir ideias de semelhanças semânticas no primeiro grupo e o segundo é formado com as ideais diferentes. Com base no estudo da teoria fundamentada, a abordagem sugere reler o texto (corpus da entrevista) diversas vezes com o intuito de descobrir ou rotular as variáveis semelhantes e diferentes. Nessa fase o corpus foi impresso em papel e destacado por cores, conforme a existência de argumentos semelhantes ou dissonantes.

O autor Scaletsky (2016) define essa abordagem como "nuvem conceitual", na qual a análise dos dados em profundidade permite a compreensão de tópicos desconhecidos. "A transformação do texto original em categorias é feita através de um referencial de codificação que abrange todo aspecto importante da pesquisa. O desafio é reduzir uma grande quantidade em unidades significativas de análise, sem perder a essência (conteúdo e intenção) do material original" (Bauer e Gaskell, 2002, p.237). 


\section{Resultados}

A investigação do corpus e o seu processamento teve como resultado a ferramenta "Design de Exposições Elementar". A análise exploratória foi construída pela junção de fragmentos das entrevistas que colaboraram para a construção posterior do modelo, partindo dessa premissa a ferramenta apresenta os desafios enfrentados pelos produtores de projeto. Além da apresentação do contexto, o estudo destacou a visualização das condições da produção colaborativa, podendo ser utilizada posteriormente para elucidar a participação e gerenciamento da equipe no desenvolvimento de exposições.

O "Design de Exposições Elementar", apresentado na figura 3, propõe perguntas relacionadas ao desenvolvimento do projeto: quem? Onde? Como? O que? Através das respostas investigam-se sistemas complexos do início do projeto. Tão importante quanto essa investigação, é a construção de um repertório dos projetos executados anteriormente, incluindo os êxitos e problemas enfrentados. Dessa forma, a empresa ou projetista constrói o registro e a replicação de procedimentos bem sucedidos.

Figura 3 - "Design de Exposições Elementar" perguntas. Fonte: Autores

\section{DESIGN DE EXPOSIÇÕES ELEMENTAR}

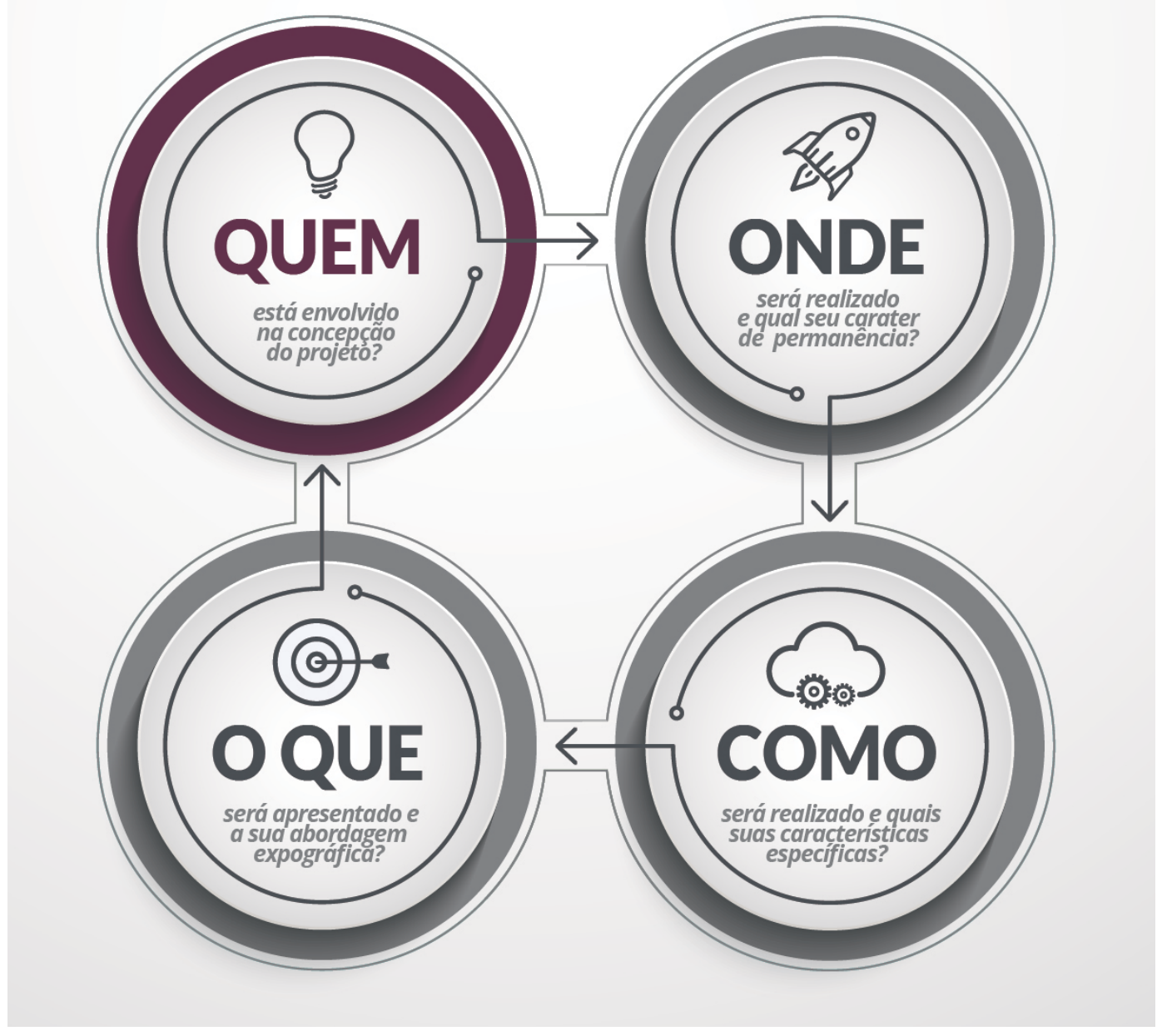


A figura 4, compreende o diagrama completo “Design de Exposições Elementar", em que são apresentadas possíveis respostas às perguntas, colaborando assim para a compreensão do essencial na realização dos projetos. Essas respostas podem ser editadas considerando contextos não descritos em completude nesta pesquisa.

Figura 4 - "Design de Exposições Elementar". Fonte: Autores

\begin{tabular}{|c|c|c|c|}
\hline REALIZADORES & PÚBLICO & DEFINITIVO & \\
\hline $\begin{array}{l}\square \text { Curadores } \\
\square \text { Promotores } \\
\square \text { Financiadores } \\
\square \text { Diretores } \\
\square \text { Museólogos }\end{array}$ & $\begin{array}{l}\square \text { Visitante } \\
\square \text { Expectador } \\
\square \text { Comprador } \\
\square \text { Educador } \\
\square \text { Alunos }\end{array}$ & $\begin{array}{l}\square \text { Museus (exposições } \\
\text { permanentes) } \\
\square \text { Empresas (espaços } \\
\text { corporativos) }\end{array}$ & \\
\hline PRODUTORES & PROMOTORES & ITINERANTE & TEMPORÁRIO \\
\hline $\begin{array}{l}\square \text { Arquitetura } \\
\square \text { Cenografia } \\
\square \text { Design Gráfico } \\
\square \text { Tecnologia } \\
\square \text { Iluminação } \\
\square \text { Sonorização } \\
\square \text { Audiovisual } \\
\square \text { Engenharia } \\
\square \text { Interatividade }\end{array}$ & $\begin{array}{l}\square \text { Marketing } \\
\square \text { Instituição } \\
\square \text { Clientes }\end{array}$ & $\begin{array}{l}\square \text { Stage (palco) } \\
\square \text { Exposições } \\
\square \text { Projeções } \\
\square \text { Eventos }\end{array}$ & $\begin{array}{l}\square \text { Vitrines } \\
\square \text { Feiras e Stands } \\
\square \text { Show/Apresentações } \\
\square \text { Salão de Exposições } \\
\square \text { Museus (exposições } \\
\text { temporárias) }\end{array}$ \\
\hline $\begin{array}{c}\text { QUEM vai participar na } \\
\text { concepção da produção } \\
\text { do projeto? }\end{array}$ & & & $\begin{array}{l}\text { ONDE é o espaço que } \\
\text { será realizado a exposição } \\
\text { e qual é o seu carater } \\
\text { de permanência? }\end{array}$ \\
\hline $\begin{array}{c}\text { OQUE será exposto? } \\
\text { E qual será a abordagem } \\
\text { expográfica/abordagem } \\
\text { narrativa? }\end{array}$ & & & $\begin{array}{c}\text { COMO será realizado? } \\
\text { Quais são as características } \\
\text { especifficas de cada } \\
\text { material? }\end{array}$ \\
\hline FUNÇÃO DA EXPO & & & MATERIALIDADE \\
\hline $\begin{array}{l}\square \text { Cultural (Social) } \\
\square \text { Promocional (Vender) } \\
\square \text { Educativo (Ensinar) } \\
\square \text { Entretenimento (Divertir) }\end{array}$ & & & $\begin{array}{l}\square \text { Estrutura } \\
\square \text { Sustentabilidade } \\
\square \text { Logística } \\
\square \text { Novas tecnologias } \\
\square \text { Limitacão de uso de }\end{array}$ \\
\hline MEDIA | INTERFACE & EXPOGRAFIA & PROTOTIPAGEM & materiais \\
\hline $\begin{array}{l}\square \text { Física } \\
\square \text { Perfomática } \\
\square \text { Gráfica } \\
\square \text { Realidade Virtual } \\
\square \text { Customizável } \\
\square \text { Interface Mista }\end{array}$ & $\begin{array}{l}\square \text { Cubo Branco } \\
\text { (contemplação) } \\
\square \text { Grafismos } \\
\text { cenográficos } \\
\square \text { Caixa Preta } \\
\square \text { Tecnologia e } \\
\text { interatividade }\end{array}$ & $\begin{array}{l}\square \text { Digital } \\
\square \text { Alta Fidelidade } \\
\square \text { Baixa Fidelidade } \\
\square \text { Maquete (escala) }\end{array}$ & \\
\hline
\end{tabular}

ONDE será realizado, caráter de permanência:

- Definitivo: museus (exposições permanentes), empresas

- Provisório: vitrines, feiras e stands, apresentações, salão de exposições

- Itinerante: stage (palco), exposições, projeções, eventos.

O espaço influencia diretamente a configuração adequada do projeto, podendo exigir mais dedicação dos integrantes em uma ou outra área específica. Geralmente essa é a primeira 
pergunta respondida, mas pode acontecer de se iniciar um projeto sem a definição do local onde será realizado.

COMO será realizada?

- Materialidade: Estrutura, sustentabilidade, logística, novas tecnologias (importação de materiais), Limitação conceitual de material pela expografia

- Prototipagem: Digital, alta fidelidade, baixa fidelidade maquete (escala).

Ao analisar as características específicas de cada material percebe-se que agrupados facilitam ou dificultam a apreensão dos conteúdos apresentados. As estruturas, na maioria das vezes, são efêmeras e enfrentarem o desafio do descarte. O caráter temporário considera que ambiente construído tem um papel próprio nas exposições.

O QUE será exposto? Qual é a abordagem expográfica?

- Função da exposição: Cultural (representar), Promocional (vender), Institucional (conectar com valores), Entretenimento (divertir e entreter)

- Mídia/ Interface: Física, performática, gráfica, realidade virtual, customizável, interface mista

- Expografia: Cubo Branco (O’ Doherty, 2002), paredes brancas contemplação da obra. Caixa Preta (Castilho, 2008), paredes pretas e ambiente imersivo. Grafismos Cenográficos (dialoga com que está sendo exposto), tecnologia e interatividade.

A interação do ambiente construído com o público, agente gerador de condições de "complexidade direcional", possibilita o desenvolvimento de projetos no qual há, em maior ou menor escala, interação entre um número considerável de variáveis, associadas a certo grau de imprevisibilidade.

QUEM são os participantes na concepção e elaboração do projeto:

- Público: Visitante, espectador, comprador, educador ou alunos

- Realizadores/as: Curadores, promotores, financiadores, diretores, museólogos

- Promotores/as: Marketing, Instituição, Clientes

- Produtores/as: Arquitetura, Cenografia, Design Gráfico (sinalização e comunicação), tecnologia, iluminação e sonorização, audiovisual, engenharia, coordenação de projetos e interatividade.

O conceito de cada exposição pode indicar que uma disciplina específica ganhe destaque. A arquitetura e o design terão que adaptar-se, por exemplo, a parâmetros luminotécnicos, acústicos, de mobiliário, conservação preventiva, plano museológico, etc. Nessas condições, torna-se fundamental criar uma estrutura de trabalho que priorize a colaboração entre os agentes. 
Depois de passar por todos os elementos do diagrama geral, a pesquisa se concentra em apresentar a aplicação no processo colaborativo (Figura 5), buscando entender e mapear estas relações, através do compartilhamento de informações. É indicado que a solução projetiva seja orgânica e partilhada pelos integrantes da equipe. Com base na construção das respostas, o gestor/a poderá ampliar a visão da complexidade do projeto: orçamento, tempo de execução, conexões e número de integrantes na equipe.

Figura 5 - Exemplo de utilização para a compreensão das relações colaborativas. Fonte: Autores

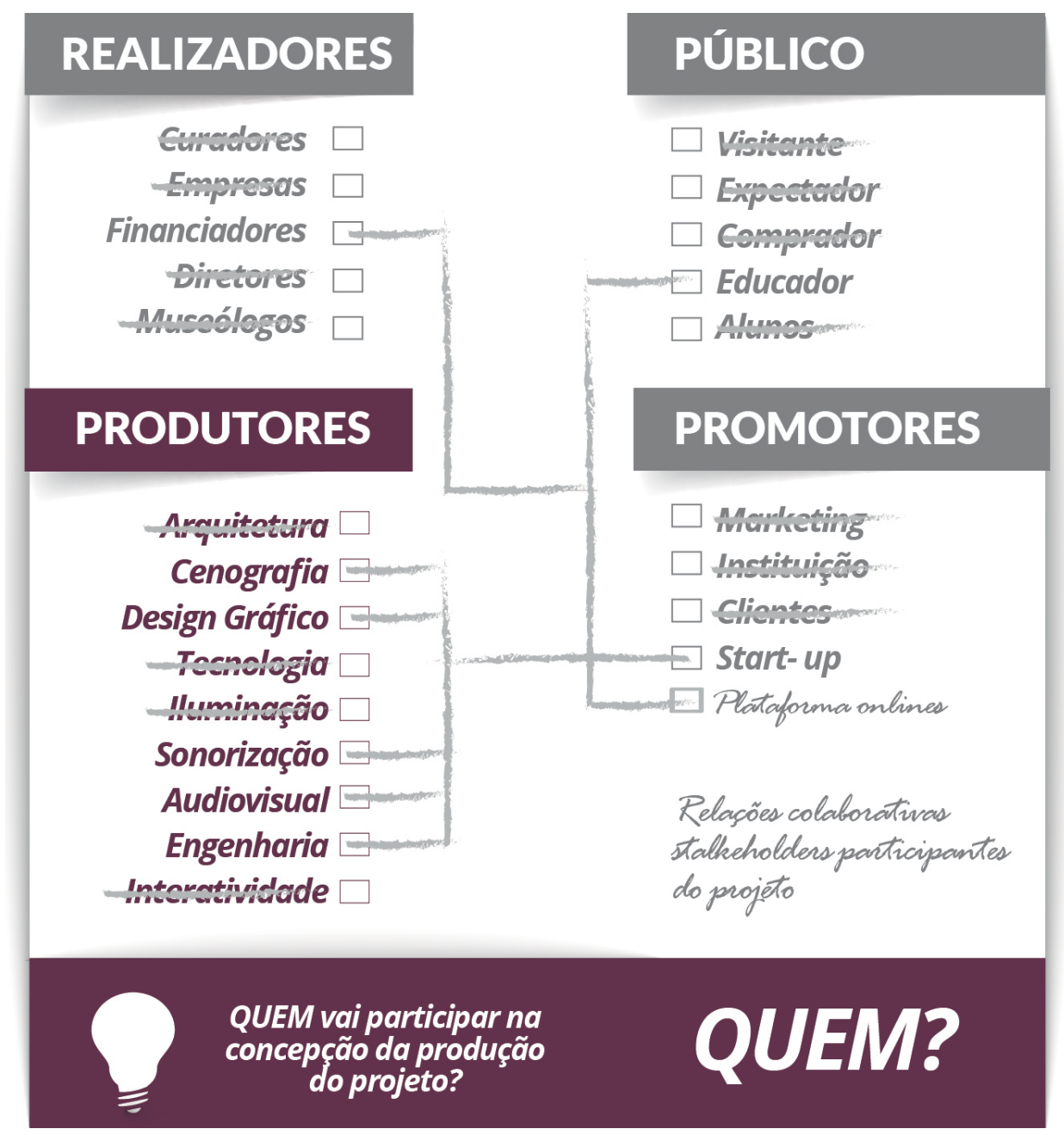

Segundo o levantamento da pesquisa, as relações que se estabelecem em equipes multidisciplinares são diferentes a cada novo projeto. Desse modo, dificultando a replicação de processos condensados e definitivos. Sendo assim, a proposta de um diagrama orgânico pode auxiliar na flexibilização e redesenho das conexões colaborativas, como observado no exemplo anterior.

Quando nos referimos à colaboração, nesta pesquisa, é necessário esclarecer que as gestoras de projetos foram fundamentais para divulgação dos processos e gerenciamento da rotina de trabalho da equipe, além da supervisão e integração dos profissionais e saberes. Para aplicação do "Design de Exposições Elementar", um/a assistente pode ser utilizado como 
interface entre as atividades que precisam ser realizadas, com os/as profissionais envolvidos/as na sua execução.

Outro critério a ser levantado na utilização da ferramenta é o compartilhamento das informações em tempo real, neste modelo de trabalho se faz necessário um feedback e uma sistematização afinada com o que está sendo apresentado. Modelos com independência e autogestão de projetos com a aplicação da ferramenta podem ser estudados e contemplados, porém, não foi esse o recorte da presente pesquisa.

Os desafios encontrados na área do Design de Exposições podem refletir em áreas afins, que possuem em sua estrutura a complexidade. Dessa maneira os projetistas podem se desafiar a aplicar a ferramenta em projetos complexos de natureza distinta. Se isso ocorrer os autores deste artigo têm grande interesse no retorno dos resultados alcançados.

\section{Discussão dos resultados}

Nesta parte do artigo, será apresentado a transformação dos dados coletados e da teoria para a ferramenta "Design de Exposições Elementar", destacando a transcrição das entrevistas e análise de mídias: vídeos de projetos, sites e apresentações institucionais das empresas.

Para Horn (1998) a linguagem visual, pode facilitar graficamente a comunicação através da combinação e integração de palavras, formas geométricas e imagens. Para Frascara (2004) a sintaxe visual é uma organização, apropriada para comunicações visuais, porque confronta o leitor a infinitas possibilidades de arranjos, em vez de criar a noção de limitação de que a palavra "sintaxe" denota (Frascara, 2004, p.16)

Para estrutura, análise e sintaxe das entrevistas foram elaboradas as seguintes categorias: procedimentos colaborativos (compreensão da existência nos projetos na empresa), desafios da colaboração e registro final dos projetos (memorial). Esses trechos foram determinantes para a reflexão sobre a colaboração em diversas fases dos projetos.

Para Bauer e Gaskell (2013) a estrutura do corpus se estabelece como uma coleção de materiais textuais que são redigidos coletados e organizados. Esses registros são utilizados para análise, reflexão e sistematização da teoria. Na tabela 1, consta a compreensão da coleta de dados pelo meio e materiais utilizados. Os sites das empresas e o estudo dos projetos se constituíram como base inicial para a realização das entrevistas e posteriormente viabilizaram a compreensão do cenário a ser explorado.

Tabela 1: Compreensão da coleta de dados - Fonte: Adaptado de Bauer e Gaskell (2013)

\begin{tabular}{ll}
\hline Meio & Material analisado (corpus) \\
\hline Entrevistas & Transcrição direta \\
Vídeos de projetos & Transcrição da narração \\
Sites das empresas & Prévia de conteúdo e informações dos projetos \\
Materiais de apresentação das empresas & Prévia de conteúdo e informações dos projetos \\
\hline
\end{tabular}


Segundo Glaser e Strauss (1967), na codificação dos dados, deve ocorrer uma comparação cuidadosa e intensa, relacionando passagens do texto (corpus). Os dados, provenientes da coleta, passaram por uma verificação minuciosa, buscando retirar dados incompletos ou dúbios, organizando conceitos elementares e seus pontos de convergência na compreensão de um desafio inicial de projeto.

Nesta parte do caminho, considera-se a abordagem de Frascara (2004) de interpretação, organização e apresentação visual da mensagem, "a sensibilidade em relação à forma deve andar de mãos dadas com sensibilidade para o conteúdo. Designers organizam não só a tipografia, mas também palavras" (Frascara, 2004, p.20). Com base nesta premissa e buscando a essência das palavras, surge o destaque do diagrama que propõe perguntas para o desenvolvimento do projeto: quem? Onde? Como? O quê? Com base nessas perguntas o modelo foi desenvolvido para visualização dos desafios de projeto.

Um requisito para a criação do diagrama foi a colaboração, os elementos visuais deveriam ser abertos a alteração e discussão pelos membros da equipe (Figura 6). Além da visualização do "elementar" a pesquisa se propôs a possibilitar a visualização da produção colaborativa, podendo ser utilizada posteriormente para elucidar as relações que se estabeleceram na participação.

Figura 6 - Apresentação do diagrama "Design de Exposições Elementar". Fonte: Autores

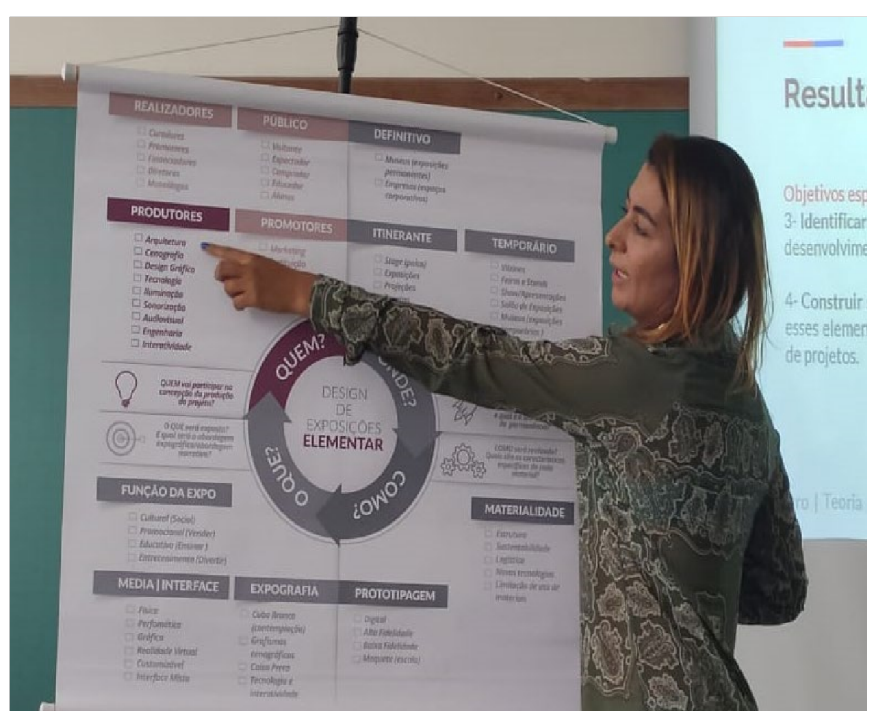

Para definição dos parâmetros essenciais de projetos expositivos, o resultado utiliza dados da teoria e análise dos textos das entrevistadas. O diagrama pode ser utilizado como um cartaz (Figura 6) ou fichas de projetos, documentados e acessados posteriormente. Com base na teoria de Jacobson (1999), o diagrama segue o objetivo do Design de Informação de desenvolver documentos compreensíveis, recuperáveis e de fácil tradução em ação. Esse modelo se apresenta orgânico e colaborativo podendo ser ampliado por pesquisadores e projetistas que tenham o interesse da utilização e discussão acerca da construção dessa modalidade de projeto. 


\section{Conclusão}

Este artigo apresentou o recorte da pesquisa de mestrado cujo objetivo foi investigar como a colaboração está inserida na produção de projetos no Design de Exposições, no contexto brasileiro. Ao final deste estudo, compreende-se que existem muitas vertentes a serem investigadas em uma área projetiva em constante ampliação e transformação.

Além disso, a investigação teórica foi importante para localizar na literatura do design esta modalidade de projeto. A partir disso entende-se que os processos criativos de projetos nacionais precisam ser descritos e divulgados para que o/a estudante que deseja ser um/a projetista de exposições tenha acesso ao "elementar" da área. A particularidade das empresas estudadas permite a observação de uma situação multifacetada que indica a transformação do Design de Exposições nas últimas décadas.

Para a coleta de dados foi utilizado o método da teoria fundamentado em dados, a aplicação de seus procedimentos foi descrita detalhadamente neste artigo. Nas entrevistas constatou-se a presença da colaboração neste contexto pelas gestoras, que se mostraram compreensíveis ao assunto, entretanto ainda é evidente a falta de sistematização de processos colaborativos em suas práticas de projeto. A escassez de documentação dificulta a compreensão da efetividade das ações no decorrer do mesmo, definir com precisão os/as componentes e atividades exige dedicação. Nesse caso se sugere que a liderança atuante no registro aconteça de maneira rotativa, para que os profissionais da equipe revezem o papel de interlocutor e coordenador das etapas.

Para sintetizar visualmente a teoria e a análise de dados foi construído o modelo de "Design de Exposições Elementar", que elucida aspectos do desenvolvimento de projetos para visualizar os atores (produtores) do projeto e entender como será estabelecida sua relação com outros participantes do desenvolvimento do projeto. O uso do termo "colaboração" é naturalizado no universo de projetos expositivos de maneira a compreender o trabalho em equipe, mas a estruturação exige esforço e comprometimento para que a interação entre os membros da equipe funcione e seja registrado. Além da integração desses fatores, necessitase da sistematização de processos tornando replicáveis as metodologias colaborativas, através do mapeamento, da identificação e da mensuração.

Conclui-se que a colaboração está presente na relação entre os produtores do projeto, situação possível de se observar em projetos reais. Como sugestão para estudos futuros sobre a ferramenta aqui apresentada: ampliação e inclusão de outros contextos. Ao final, considerar exemplares em um recorte específico, cidade do Rio de Janeiro e cidade de São Paulo, permite uma análise pontual, deixando margem para execução da ferramenta em outros estudos com abrangências diversas, capazes de promover o entendimento compartilhado das especificidades de produção. Compreende-se nesse trabalho que a cultura de colaboração viabiliza a integração dos produtores nos projetos expositivos. 


\section{Agradecimentos}

Os autores agradecem a CAPES e ao CNPq pelo apoio na forma de bolsa de estudos.

\section{Referências}

Moraes, M. (2020). A colaboração no design de exposições. Dissertação (Mestrado em Design) Programa de Pós graduação em Design, Universidade Federal do Paraná - UFPR, Curitiba.

Heemann et al. (2008). Compreendendo a Colaboração em Design de Produto. Actas de Diseño. Facultad de Diseño y Comunicación. Universidad de Palermo. ISSN 1850-2032

Holstein, J. A.; Gubrium, J. F. (2008). Handbook of Constructionist Research. London: Guilford Press.

Frascara, J. (2004). Communication design: principles, methods, and practice. New York: Allworth Press

Bauer, W; Gaskell, G. (2002). Pesquisa qualitativa com texto imagem e som: um manual prático - 2. ed - tradução de Pedrinho A. Guareschi — Petrópolis, RJ: Vozes.

O' Doherty, B. (2002). No interior do cubo branco. A ideologia do espaço da arte. 1. ed. - São Paulo: Martins Fontes.

Jacobson, R (1999). Information Design. Massachusetts: The MIT Press.

Horn, R (1998). Visual Language: Global Communication for the 21st Century. MacroVU, Incorporated.

Strauss, A. L; Corbin, j. (1998). Basics of qualitative research: techniques and procedures for developing grounded theory. Thousand Oaks, CA: Sage publication.

Glaser, B. G; Strauss, a. L. (1967). The discovery of grounded theory. Strategies for qualitative research. Chicago: Aldine.

Scaletsky, C. (2016). Design estratégico em ação. São Leopoldo: Ed Unisinos.

\section{Entrevistas}

Brazil, L. V. Entrevista concedida. Rio de Janeiro, RJ. Novembro de 2019.

Abreu, B. \& Abreu, M. Entrevista concedida. São Paulo, SP. Novembro de 2019.

Kalman, M. Entrevista concedida. São Paulo, SP. Novembro de 2019.

\section{Sobre os autores}

Marina Moraes, Msc., UFPR, Brasil <marinamoraes.design@gmail.com >

Adriano Heemann, Dr., UFPR, Brasil < adriano.heemann@gmail.com> 